\title{
Circulating protein and antibody biomarker for personalized cancer immunotherapy
}

Jianda Yuan

\begin{abstract}
Immune checkpoint blockade therapies are revolutionizing standard cancer treatments. Immune checkpoint inhibitors likely function to enhance the tumor specific antigen response in order to achieve favorable clinical outcomes. Thus, continuous efforts to identify the common tumor-specific antigens are essential for the broad clinical application of these therapies. Several immunoproteomics approaches have been used in order to screen for this specificity. In a recent article from Jhaveri and colleagues published in the February issue of Cancer Immunology Research, antibody biomarkers were screened in pancreatic cancer patients who received allogeneic, granulocyte-macrophage colony stimulating factor-secreting pancreatic cancer vaccine (GVAX) by using a serum antibody-based SILAC immunoprecipitation (SASI) approach. Using this assay, several new tumor antigens (MYPT1, PSMC5 and TRFR) were identified that were found to have significantly different expression in tumors compared with normal tissue. Moreover, patients with detectable antibodies showed improved disease-free survival after GVAX therapy. These targets need to be further validated to determine the full spectrum of tumor antigen immunogencity and their potential clinical application. In addition to antibodies, circulating protein, DNA and RNA in peripheral blood are under clinical investigation as liquid biopsies and have the potential to provide guidance for future personalized cancer immunotherapy.
\end{abstract}

Keywords: Antibody response, Antigen discovery, Mass spectrometry, Liquid biopsy, Biomarker and personalized cancer immunotherapy

\section{Background}

Immune checkpoint blockade therapies are revolutionizing standard cancer treatments [1]. It is a paradigm shift within cancer immunotherapy from a focus on stimulating the immune system to a focus on releasing the checkpoint inhibitors resulting in adequate immune and tumor responses [2]. Tumor rejection antigens allow tumors that are distinct from normal tissue to activate the immune system and generate robust anti-tumor responses [3]. Immune checkpoint blockade enhances the tumor rejection response mediated by these antigens to achieve favorable clinical outcomes. Therefore, it is of importance to identify the right tumor rejection antigens to provide important therapeutic guidance for future cancer immunotherapy. Novel high-throughput technology such as whole exome sequencing allows the systemic analysis of the mutation load of the tumor as well as the

Correspondence: jianda.yuan@merck.com

Oncology Clinical Research, Merck Research Laboratories, Rahway 07065, NJ, USA

(C) 2016 The Author(s). Open Access This article is distributed under the terms of the Creative Commons Attribution 4.0 International License (http://creativecommons.org/licenses/by/4.0/), which permits unrestricted use, distribution, and reproduction in any medium, provided you give appropriate credit to the original author(s) and the source, provide a link to the Creative Commons license, and indicate if changes were made. The Creative Commons Public Domain Dedication waiver (http://creativecommons.org/publicdomain/zero/1.0/) applies to the data made available in this article, unless otherwise stated. 
to assess the antibody profile in patient sera by using proteins employed on a membrane. NY-ESO-1 was the first cancer testis antigen discovered by SEREX technology. The application of SERPA and SEREX technologies is relatively limited due to the assay specificity and the complexity of the assay preparation and procedure. In addition, the proteins on SEREX membrane expressed by tumor cDNA phase library in bacterial do not account for human posttranslational modification.

Protein microarrays are based upon the development of DNA microarray techniques and have thousands of purified proteins immobilized on a solid surface. Protein microarrays are generally classified into three types: analytical, functional and reverse-phase protein microarrays. ProtoArray ${ }^{\circ}$, a functional array, offers a unique approach to analyze the serological response against thousands of protein at the same time. This approach is limited by the number of proteins coated on the slides (e.g., not all human proteins are present, and mutated or modified versions of proteins may not be available) [7].

\section{Main text}

In the February issue of Cancer Immunology Research [8], Jhaveri and colleagues used quantitative seroproteomics to identify antibody biomarkers in pancreatic cancer patients treated with allogeneic, granulocytemacrophage colony stimulating factor-secreting pancreatic cancer vaccine (GVAX). The authors took advantage of stable, isotope-labeled amino acids (SILAC) in pancreatic ductal adenocarcinoma cell culture, immune precipitation with patient-derived antibodies and mass spectrometric analysis. They developed a serum antibodies-based SILAC immuneprecipitation (SASI) approach to identify antibody response elicited by the vaccination.

In this study, pre-vaccine sera was intentionally subtracted from post-vaccine sera in order to assess the vaccine-induced specific antibody responses. In doing so, a few antibodies were identified as targets from postvaccination samples in patients with favorable clinical outcome. The expression of three antigens (MYPT1, PSMC5 and TRFR) was measured in tumor and normal duct epithelium, and significant differences were found in the expression of these three antigens in tumor compared with normal tissue. Moreover, patients with detectable identified antibodies showed improved diseasefree survival.

Overall, the SASI approach was found to identify new tumor antigens as potential biomarkers and therapeutic targets. This approach could also be applied to other similar clinical studies without protein synthesis, but these new targets require further validation as possible pancreatic cancer biomarkers. The caveat and potential limitation of this study is the subtraction of pre-vaccine sera. It limits the ability to identify the baseline antibody response, which may predict the patient's response to GVAX vaccination. In addition, allogeneic tumor cells instead of autologous tumor cell lines were used for the vaccination. Thus, targets from autologous tumor cells may be partially missed because of the limitation of the allogeneic tumor immunogenicity profile.

\section{Perspective and future directions}

The SASI approach is an effective method to identify tumor-specific antigens, especially common tumor rejection antigens that would allow for the development of "off-the-shelf" vaccinations. In addition to the validation of the expression and distribution of these new targets, it is of importance to further characterize these antibodies and the antigen-specific CD4+ and CD8+ T cell response. The dissociation between antibody responses and antigen-specific $\mathrm{CD} 8^{+} \mathrm{T}$-cell responses is frequently observed with other tumor antigens. CTLA-4 blockade induced a broad antibody response in cancer patients with ovarian, prostate cancer and melanoma $[9,10]$. Advanced melanoma patients with integrated immune responses to NY-ESO-1 antigen had a favorable clinical course after ipilimumab treatment [11]. The majority of NY-ESO-1 seropositive patients without detectable NYESO-1-specific $\mathrm{CD} 8^{+} \mathrm{T}$ cells did not experience clinical benefit. Therefore, cellular tumor antigen-specific CD4+ and $\mathrm{CD} 8+\mathrm{T}$ cell response needs to be evaluated to obtain the full spectrum of the identified antigens immunogencity and explore the potential clinical application.

Antibodies are useful for the discovery of tumorspecific antigens. Moreover, antibodies may be able to directly or indirectly eliminate tumor cells through opsonization, antigen presentation to $\mathrm{T}$ cells and by initiating NK cells or complement-dependent cell toxicity [12]. Several potential clinical applications of antibodies including antibody-drug conjugates, antibody cytokine fusions and bispecific/multispecific antibodies are under clinical investigation. A low success rate of current monoclonal antibody therapy is likely due to low sensitivity and specificity. Sensitivity and specificity of the target is critical for successful application [13].

In addition to antibodies, proteins circulating in blood could be potential biomarkers for cancer immunotherapy. As an example, patients with low baseline vascular endothelial growth factor (VEGF) experienced better clinical outcome in advanced melanoma patients treated with ipilimumab. Thus, serum VEGF may be a predictive biomarker for ipilimumab treatment [14]. With advances in mass spectrometry-based serum assays, automated database search algorithms and the proteome discoverer software platform, a mass spectrometry-based serum assay was recently developed to predict clinical outcome in patients treated with PD-1 blockade [15]. Fifty-nine 
mass spectral (MS) selected from 351 MS identified from the results of baseline serum were defined as DBX008+ and DBX008-. Patients with DBX008+ have a better time to tumor progression and overall survival than patients with DBX008-. Similar to VEGF, these MS themselves in the peripheral blood may have immunomodulatory impacts on human immune cells. The amount of these MS may also be associated with immune suppression or activation in tumor microenvironment. Further characterization of these MS will provide additional information to understand mechanism of action in these patients treated with immune checkpoint blockade.

Besides proteins and antibodies, tumor cells can also release DNA and RNA into the blood by a variety of microvesicle-dependent or -independent mechanisms. Novel technologies with minimal specimen requirements allow the characterization of these tumor derived DNA and RNA. Liquid biopsies including cell-free circulating tumor DNA (ctDNA) from plasma have been investigated for non-invasive detection and monitoring of patient tumors as well as potential biomarkers for cancer immunotherapies [16, 17]. The validation of these assays focused on the serial analyses of DNA, RNA and protein/antibody in peripheral blood will allow us to identify changes in the tumor in real time, detect tumor response or relapse early, identify potential pharmacodynamic/pharmacokinetic predictive biomarkers related to the treatment, understand the resistance mechanisms and provide guidance for future monotherapy or combination personalized cancer immunotherapy.

\section{Acknowledgments}

The author sincerely thanks Dr. Chelsey Meier from the Society for Immunotherapy of Cancer (SITC) for comments and editorial assistance.

\section{Authors' contributions}

JY drafted the manuscript. JY read and approved the final version of this manuscript.

\section{Authors' information}

The author is currently Director of Translational Immuno-Oncology Research at Merck \& co. Inc. and responsible for translational immune-oncology research to meet the need of clinical Immuno-Oncology drug development. From 2002 through February 2016, the author was employed at the Memorial Sloan Kettering Cancer Center, where he established and directed the immune monitoring core for translational biomarker research.

\section{Competing interest}

The author declares that he has no competing interests.

Received: 4 May 2016 Accepted: 18 July 2016

Published online: 16 August 2016

\section{References}

1. Yuan J, Hegde PS, Clynes R, Foukas PG, Harari A, Kleen TO, Kvistborg P, Maccalli C, Maecker HT, Page DB, et al. Novel technologies and emerging biomarkers for personalized cancer immunotherapy. J Immunother Cancer. 2016;4:3.
2. Gajewski TF. Improved melanoma survival at last! Ipilimumab and a paradigm shift for immunotherapy. Pigment Cell Melanoma Res. 2010;23:580-1.

3. Gilboa E. The makings of a tumor rejection antigen. Immunity. 1999:11:263-70.

4. Snyder A, Makarov V, Merghoub T, Yuan J, Zaretsky JM, Desrichard A, Walsh LA, Postow MA, Wong P, Ho TS, et al. Genetic Basis for Clinical Response to CTLA-4 Blockade in Melanoma. N Engl J Med. 2014;371:2189-99.

5. Schumacher TN, Schreiber RD. Neoantigens in cancer immunotherapy. Science. 2015:348:69-74

6. Old LJ. Cancer immunology: the search for specificity-G. H. A. Clowes Memorial lecture. Cancer Res. 1981:41:361-75.

7. Yuan J, Wang E, Fox BA. Immune Monitoring Technology Primer: protein microarray ('seromics'). J Immunother Cancer. 2016:4:2.

8. Jhaveri DT, Kim MS, Thompson ED, Huang L, Sharma R, Klein AP, Zheng L, Le DT, Laheru DA, Pandey A, et al. Using Quantitative Seroproteomics to Identify Antibody Biomarkers in Pancreatic Cancer. Cancer Immunol Res. 2016:4:225-33.

9. Hodi FS, Oble BD, et al. Immunologic and clinical effects of antibody blockade and cytotoxic T lymphocyte-associated antigen 4 in previously vaccinated cancer patients. Proceedings of the National Academy of Sciences of the United States of America. 2008;105:3005-10.

10. Fong L, Kwek SS, O'Brien S, Kavanagh B, McNeel DG, Weinberg V, Lin AM, Rosenberg J, Ryan CJ, Rini Bl, et al. Potentiating Endogenous Antitumor Immunity to Prostate Cancer through Combination Immunotherapy with CTLA4 Blockade and GM-CSF. Cancer Research. 2009;69:609-15.

11. Yuan J, Adamow M, Ginsberg BA, Rasalan TS, Ritter E, Gallardo HF, Xu Y, Pogoriler E, Terzulli SL, Kuk D, et al. Integrated NY-ESO-1 antibody and CD8+ Tcell responses correlate with clinical benefit in advanced melanoma patients treated with ipilimumab. Proc Natl Acad Sci U S A. 2011;108:16723-8.

12. Jhaveri DT, Zheng L, Jaffee EM. Specificity delivers: therapeutic role of tumor antigen-specific antibodies in pancreatic cancer. Semin Oncol. 2014:41:559-75.

13. Imai K, Takaoka A. Comparing antibody and small-molecule therapies for cancer. Nat Rev Cancer. 2006;6:714-27.

14. Yuan J, Zhou J, Dong Z, Tandon S, Kuk D, Panageas KS, Wong P, Wu X, Naidoo J, Page DB, et al. Pretreatment serum VEGF is associated with clinical response and overall survival in advanced melanoma patients treated with ipilimumab. Cancer Immunol Res. 2014;2:127-32.

15. Weber J, Roder H, Asmellash S, Meyer K, Sayers K, Steingrimsson S, Roder J. A mass spectrometry-based serum test to predict outcome of treatment with nivolumab: Analysis of samples taken during therapy. Poster 4891, 2016, AACR conference, April 16-20, New Orleans.

16. Crowley E, Di Nicolantonio F, Loupakis F, Bardelli A. Liquid biopsy: monitoring cancer-genetics in the blood. Nat Rev Clin Oncol. 2013;10:472-84.

17. Diaz LA, Jr, Bardelli A. Liquid biopsies: genotyping circulating tumor DNA. J Clin Oncol. 2014;32:579-86.
Submit your next manuscript to BioMed Central and we will help you at every step:

- We accept pre-submission inquiries

- Our selector tool helps you to find the most relevant journal

- We provide round the clock customer support

- Convenient online submission

- Thorough peer review

- Inclusion in PubMed and all major indexing services

- Maximum visibility for your research

Submit your manuscript at www.biomedcentral.com/submit
Biomed Central 